\title{
РЕТРОСПЕКТИВНЫЙ АНАЛИЗ ГОСУДАРСТВЕННЫХ ФИНАНСОВЫХ РЕСУРСОВ ТЕРРИТОРИЙ В РОССИИ
}

\author{
(C) 2019 Валиева Елизавета Николаевна \\ доктор экономических наук, профессор кафедры финансов и кредита \\ Самарский государственный экономический университет \\ 443090, г. Самара, ул. Советской Армии, д. 141 \\ E-mail: rad8063@yandex.ru
}

Институциональные особенности предшествовавших исторических периодов оказывают существенное влияние на характер и особенности развития эконмических отношений в настоящем. Ретроспективное исследование формирования и использования государственных финансовых ресурсов административно-территориальных формирований России может способствовать пониманию современных межбюджетных отношений в РФ, а также обоснованию направлений их совершенствования и инструментов развития. Степень разработанности. Вопросы государственных финансов и управления ими на различных этапах исторического развития рассматривались в работах Евзлина 3., Горлова И. (империалистический период), Тархова С., Мееровича М. (советский период), Горегляда В., Татаркина А., Швецова Ю. (современный бюджетный федерализм). Однако в сравнительном аспекте данная проблематика в публикациях не представлена. Теоретико-методологическое значение работы заключается в выявлении особенностей бюджетной политики России и бюджетных отношений на значимых этапах ее экономической истории. Практическое значение для обоснования целей бюджетной стратегии РФ могут иметь сформулированные выводы и предложения.

Ключевые слова: государственные финансовые ресурсы, межбюджетные отношения, расходы территориальных бюджетов, налоговая политика, история государственных финансов в России.

Структура органов власти государства, их место в системе управления, делегированные полномочия и источники финансирования определяются сложившимся в результате исторического развития административно-территориальным делением. Зарождение бюджетных отношений в России принято относить к эпохе царствования Ивана IV (Грозного). Первоначальная цель административно-финансовой реформы Ивана IV заключалась в обеспечении удобства сбора податей и налогов, а также защиты государства от внешних врагов внутренней княжеской смуты. Земская, губная и налоговая реформы заложили основы местного самоуправления. Выбранные общиной старосты отвечали за правопорядок на местах и сбор по установленным правилам податей в казну московского князя.

Расходование средств казны осуществлялось приказами: посольским (внешняя политика), разрядным (оборона), поместным (земельные отношения), земским (охрана общественного правопорядка) и др. В отличие от западной Европы, границы средневековых феодальных княжеств для административно-территориального деления России значение не имели, хотя и учитывались. Так, до административной реформы Петра I в России насчитывалось 166 уездов (прежних княжеских земель, уделов, приказов, разрядов и т.д.), это не считая многих волостей, часть из которых была близка к уездам. Петровская реформа 1708 года разделила страну на 8 огромных губерний, которые составлялись из городов и прилегающих к ним земель, а также разрядов и приказов.

По мере формирования Российской империи, добавился еще один принцип административно-территориального деления - национальный, позволяющий удерживать завоёванные территории в составе государства через предоставление народам, населяющим данные земли признаков собственной государственности и некоторых привилегий по сравнению с другими единицами.

B XIX веке значительно усилилась экономическая составляющая, оказывающая влияние на административно-территориальное деление страны. Помимо оптимизации сбора налогов, ведущую роль стали играть географически и климатически однородные территории, которые позволяли рационализировать процесс сельскохозяйственного производства, концентрируя их 
вокруг единого крупного городского центра.

К 1917 году Российская империя насчитывала более 80 губерний, областей и краёв, 4 генерал-губернаторств, 3 самостоятельные области на правах губерний [7]. При этом необходимо отметить, что экономическая и национальная составляющие были основой для административно-территориального деления страны. Учитывая, что Российская империя была унитарным государством, государственное финансовое управление в ней заключалось в наполнении казны доходами и осуществлении государственных расходов непосредственно из центра. Учёные того времени делили доходные источники на налоги, промышленные доходы и пошлины. Преобладающими доходами в бюджете Российской империи являлись косвенные налоги на потребительские товары, в том числе доходы от винной монополии. На прямые налоги приходилось менее 10\% доходов бюджета [3].

Налоги в то время считались «самым типичным источником доходов, на котором основывается всё финансовое хозяйство современных государств». Они рассматривались «платой за такие из оказываемых услуг, полезность которых чувствуется всеми жителями государства, но которые по своей природе не делимы». Прямые налоги делились на несколько видов. Во-первых, личные налоги или подушная подать, которые взимались в равных размерах со всех граждан. К 1917 году такие налоги сохранились лишь в «обложении кочевых народов и в царстве Польском». Во-вторых, имущественные налоги, к которым относились поземельный налог, налог на строения, основной промысловый налог. В-третьих, подоходные налоги [1].

К промышленным доходам относились поступления от государственных предприятий, которые состояли из доходов казённых предприятий, в том числе сельскохозяйственных, и аренды земли, доходов от государственной «Винной монополии», доходов от «государственных регалий» - чеканки монет и почтово-телеграфных, наконец, доходов, полученных государством от того, что сегодня называется государственно-частным партнёрством.

Пошлины взимались за оказание конкретных государственных услуг, к которым относились услуги по обеспечению внешней безопасности (консульские сборы) и внутренней безопасности (судебные сборы, межевые работы, карантинные сборы и т.д.) частных лиц, разви- тие образования, науки и искусства (учебные сборы за слушание лекций, сборы на содержание слушателей, учеников и пенсионеров и т.д.), а также в целях содействия промышленности и торговле (торговые и промышленные пошлины, сборы за выверку и клеймение мер и весов, привилегии за право собственности на фабричные рисунки и знаки, судоходные пошлины и т.д.).

Расходы государства делились также на три больших группы: реальные или действительные государственные расходы, фискальные расходы и промышленные расходы.

Реальные расходы осуществлялись с целью:

- предоставления общественных благ и государственных услуг, куда входили финансирование национальной обороны и правоохранительной деятельности, народного образования на низших уровнях, науки и искусства;

- субсидирование и поддержку высшего образования, религии, осуществления так называемых общественных работ, необходимых обществу, но непривлекательных для частного капитала (осушение болот, мелиорация, обеспечение судоходства, строительство железных дорог и дорог вообще и т.д.), развития промышленности;

- финансирование государственного управления;

- обслуживание государственного кредита.

Расходы государства осуществлялись централизованно. Губернии финансировались из государственного бюджета Российской Империи с целью обеспечения денежными средствами государственных расходов на территориях губерний.

Таким образом, половина доходов бюджета формировалась за счет косвенных налогов - таможенных пошлин и фискальных монопольных налогов. Налоги на бизнес составляли менее десяти процентов, за исключением поступающей прибыли от принадлежащих государству железных дорог. Бюджетная отчетность Российской империи позволяет оценить объем доходов, передаваемых в губернии, только опосредованно на основе анализа расходов бюджета и выделения в их составе территориальной составляющей. Структура доходов Бюджета Российской Империи представлена в табл. 1.

Результаты проведенной нами экспертной оценки расходов губерний в абсолютных цифрах, а также анализ их ведомственной структуры представлены в табл. 2 . 
Таблица 1. Анализ структуры доходов бюджета России в 1913 году.

\begin{tabular}{|l|c|c|}
\hline \multicolumn{1}{|c|}{ Доходы обыкновенного бюджета России } & млн. руб. & Процент к итогу \\
\hline $\begin{array}{l}\text { Налоги(поземельный, с недвижимых имуществ, промысловый), } \\
\text { сбор с доходов денежных капиталов }\end{array}$ & 273 & 8 \\
\hline Таможенный, сахарный, питейный акциз и сборы & 708 & 20 \\
\hline Гербовые, судебные пошлины, сборы с переходящих имуществ & 231 & 7 \\
\hline Доходы от винной монополии и почтовых учреждений & 1025 & 30 \\
\hline Прибыль казенных железных дорог & 1044 & 31 \\
\hline Прочие доходы & 137 & 4 \\
\hline Всего доходов & 3421 & 100 \\
\hline
\end{tabular}

Источник. Ежегодник Министерства финансов. Вып.1915 г. Пг., 1915.

Таблица 2. Расходы, возложенные на губернии Российской Империи в 1913 году в разрезе ведомств

\begin{tabular}{|l|c|c|c|}
\hline \multicolumn{1}{|c|}{ Расходы } & млн. руб. & $\begin{array}{c}\text { Процент к } \\
\text { итогу }\end{array}$ & $\begin{array}{c}\text { Доля в обыкновенных } \\
\text { расходах Российской } \\
\text { Империи }\end{array}$ \\
\hline Ведомство священного синода & 39 & 12 & 73 \\
\hline Министерство внутренних дел & 30 & 9,3 & 2 \\
\hline Почта и телеграф & 2 & 0,6 & 16 \\
\hline Министерство финансов & 58 & 17,9 & 0,0 \\
\hline Министерство иностранных дел & 0,0 & 0,0 & 0,0 \\
\hline Министерство народного просвещения & 122 & 37,7 & 25 \\
\hline Министерство путей сообщения & 3 & 0,9 & 0,0 \\
\hline $\begin{array}{l}\text { Министерство торговли и промышленности, } \\
\text { главное управление землеустройства, главное } \\
\text { управление государственного коннозаводства }\end{array}$ & 51 & 15,7 & 0,0 \\
\hline Военное министерство & 7 & 2,2 & 85 \\
\hline Морское министерство & 1 & 0,3 & - \\
\hline Государственный контроль & 11 & 3,4 & 10 \\
\hline Платежи по государственным займам & - & - & 100 \\
\hline Всего расходов & 324 & & \\
\hline
\end{tabular}

Источник. Ежегодник Министерства финансов. Вып.1915 г. Пг.,1915.

Как видно из таблицы для Российской Империи характерна значительная централизация управления государственными финансовыми ресурсами. Можно сказать, что губернии финансировали «духовное окормление» и просвящение народа, а также государственные структуры, осуществлявшие контрольную деятельность. Некоторые полномочия имелись в сферах экономики, финансов и охраны правопорядка.

Основа административно-территориального деления РСФСР закладывалась в конце 20 -х - начале 30-х годов прошлого века. В условиях индустриализации и коллективизации, происходило формирование так называемых «хозяйственно-экономических районов» с приписанными им конкретными функциями в рамках общегосударственного плана промышленного производства. Эти районы, соразмерные друг с другом по количеству населения назывались «экономически законченными», так как обладали рядом признаков, которые либо имелись, либо формировались искусственно. К ним относились:

- наличие промышленно-пролетарского «ядра»;

- размещение населения в привязке к промышленному и сельскохозяйственному производству;

- необходимое для организации производства количество населения (необходимые трудовые ресурсы);

- определённая комбинация природных особенностей (т.е. наличие комплекса местных сырьевых ресурсов, необходимых для обеспечения производства);

- наличие транспортных ареалов, связыва- 
ющих данный район с другими в единые производственные цепочки;

- распределительная система.

В Конституции РСФСР 1978 года говориться, что экономика республик является составной частью единого народно-хозяйственного комплекса, «охватывающего все звенья общественного производства, распределения и обмена на территории СССР. При этом руководство экономикой «осуществляется на основе государственных планов экономического и социального развития, с учётом отраслевого и территориального принципов при сочетании централизованного управления с хозяйственной самостоятельностью и инициативой предприятий, объединений и других организаций». К ведению республик, в том числе относилось проведение единой социально-экономической политики, руководство экономикой, а также разработка и утверждение государственных планов экономического и социального развития, бюджета и утверждение отчета об их исполнении; руководство осуществлением государственных бюджетов автономных республик, бюджетов краев, областей и городов республиканского подчинения [4].

Таким образом, в СССР была создана иерархическая структура власти, а также бюджетного устройства, при которой вышестоящие органы определяли решения нижестоящих органов. Края и области относились к органам местной власти и наделялись финансовыми ресурсами из бюджетов союзных республик. Практики самостоятельного управления государственными финансовыми ресурсами на уровне административно-территориальных образований в Советском Союзе не было.

Попытаемся выявить фактически имевшие место задачи и бюджетные полномочия территорий в СССР посредством анализа структуру доходов и расходов государственного бюджета СССР и РСФСР в 1985 году, когда начались экономические реформы, положившие начало рыночным преобразованиям. (табл. 3).

Данные табл. 3. свидетельствуют, что доходы Государственного бюджета СССР были разделены между центром и республиками практически поровну, что свидетельствует о значительной роли последних в реализации финансовой политики страны. Основным налоговым доходом союзного бюджета были платежи из прибыли, бюджетов республик - налог с оборота. Налоги с населения были поделены паритетно.

Следует отметить, что в разные годы в зависимости от экономической политики, проводимой центральными властями СССР, доля основных налогов в структуре доходов изменялась. Так в период бурного промышленного роста, большинство получаемых доходов приходилось на отчисления от прибыли предприятий - более тридцати процентов. Ближе к 90-м годам прошлого века, когда акценты были смещены от директивного развития промышленного произ-

Таблица 3. Сравнительный анализ доходов союзного бюджета и бюджетов союзных республик в составе СССР в 1985 году

\begin{tabular}{|c|c|c|c|c|c|c|}
\hline 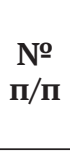 & Вид доходов & $\begin{array}{l}\text { союзный } \\
\text { бюджет } \\
\text { млрд. } \\
\text { руб. }\end{array}$ & (\%) & $\begin{array}{l}\text { бюджеты } \\
\text { союзных } \\
\text { респу- } \\
\text { блик }\end{array}$ & (\%) & $\begin{array}{l}\text { Доля союзного } \\
\text { бюджета в бюд- } \\
\text { жетах союзных } \\
\text { республик (\%) }\end{array}$ \\
\hline & Всего доходов & 114,91 & 100 & 137,3 & 100 & 84 \\
\hline \multirow[t]{2}{*}{1.} & $\begin{array}{l}\text { Поступления от социалистиче- } \\
\text { ского хозяйства }\end{array}$ & 101,23 & 88,1 & 119,3 & 86,9 & 85 \\
\hline & в том числе: & & & & & \\
\hline 1.1 & налог с оборота & 27 & 23,5 & 71 & 51,7 & 38 \\
\hline 1.2 & $\begin{array}{l}\text { платежи государственных } \\
\text { предприятий и хозяйственных } \\
\text { организациии из прибыли }\end{array}$ & 74 & 64,4 & 46 & 33,5 & 161 \\
\hline 1.3 & $\begin{array}{l}\text { подоходный налог с кооператив- } \\
\text { ных и общественных предприя- } \\
\text { тий }\end{array}$ & 0,23 & 0,2 & 2,3 & 1,7 & 10 \\
\hline 2. & Налоги с населения & 13 & 11,3 & 17 & 12,4 & 76 \\
\hline 3. & $\begin{array}{l}\text { Поступления от реализации } \\
\text { облигаций государственных } \\
\text { внутренних займов }\end{array}$ & 0,68 & 0,6 & 1,0 & 0,7 & 68 \\
\hline
\end{tabular}

Источник. Государственный бюджет СССР 1981-1985 (Статистический сборник). Москва. 1987. 214 с. 
водства к развитию хозяйственной инициативы на первое место были поставлены задачи, связанные с реализацией, в том числе имущества предприятий. В результате вырос налог с оборота и составил около трети поступлений в государственный бюджет СССР. При этом доля отчислений из прибыли предприятий за период с 1981 по 1991 годы уменьшились с 28,8\% до 23,4\% [5].

Расходы государственного бюджета СССР учитывали сложившуюся структуру доходов и были направлены на рост основных доходных источников, то есть на финансирование промышленности и сельского хозяйства. Цель экономической и финансовой политики СССР заключалась в обеспечении роста экономической мощи страны и, как следствие, возрастания благосостояния населения, в том числе за счет общественных фондов потребления. Наблюдался постоянный рост доходов населения, которые давали около 20\% поступлений в бюджет, что делало их заметным источником пополнения государственной казны. Проанализируем распределение расходов между союзным центром и республиками в 1985 году.

Как видно из табл. 4, финансирование экономики осуществлялось статистически паритетно союзным центром и республиками. Полномочия по финансовому обеспечению образования, здравоохранения и социальной поддержке насе- ления возлагались на регионы. Наука и оборона обеспечивались финансовыми ресурсами исключительно из союзного бюджета. Сопоставление общего объема доходов и расходов союзного бюджета и бюджетов союзных республик свидетельствует, что доля собственных источников в республиканских бюджетах составляла порядка $75 \%$, в союзном бюджете - 60\%. Таким образом, поддержание финансовой устойчивости бюджетов территорий являлось приоритетной целью.

Рыночные реформы начала 90-х годов $\mathrm{XX}$ века кардинально изменили бюджетное устройство в Российской Федерации. Основным отличительным признаком современной бюджетной системы Российской Федерации является самостоятельность бюджетов, а так же разграничение доходных источников бюджетов различных уровней на основе принципов бюджетного федерализма [6]. Правительства регионов самостоятельно организуют бюджетный процесс и отвечают за него на всех стадиях. Следовательно, по сравнению с предшествовавшими историческими периодами повышается роль административно-территориальных образований в достижении федеральных стратегических и тактических социально-экономических целей и, кроме того, ответственность за результаты выполнения государственных функций на субфедеральном уровне [2]. Выясним, как это отразилось на распределении доходов и расходов

Таблица 4. Анализ структуры расходов государственного бюджета СССР за 1985 год

\begin{tabular}{|c|c|c|c|c|c|}
\hline Направления расходов & $\begin{array}{c}\text { Союзный } \\
\text { бюджет } \\
\text { млрд. руб. }\end{array}$ & \% к итогу & $\begin{array}{c}\text { Бюджеты } \\
\text { союзных } \\
\text { республик, } \\
\text { млрд. руб. }\end{array}$ & \% к итогу & $\begin{array}{c}\text { Доля союзного } \\
\text { бюджета в бюд- } \\
\text { жетах союэных } \\
\text { республик (\%) }\end{array}$ \\
\hline Всего расходов, в том числе & 203 & 100 & 183 & 100 & 111 \\
\hline на народное хозяйство & 119 & 59 & 101 & 55 & 118 \\
\hline $\begin{array}{l}\text { на социально-культурные меро- } \\
\text { приятия и науку, } \\
\text { в том числе }\end{array}$ & 48 & 24 & 78 & 43 & 61 \\
\hline Науку & 13 & 6 & 1 & 0,5 & 1300 \\
\hline Прсвещение & 6 & 3 & 30 & 16 & 20 \\
\hline $\begin{array}{l}\text { печать, искусство, } \\
\text { телевидение ирадиовещание }\end{array}$ & 1 & 0,5 & 1 & 0,5 & 100 \\
\hline Здравоохранение & 1 & 0,5 & 17 & 10 & 6 \\
\hline социальное обеспечение & 3 & 1 & 29 & 16 & 10 \\
\hline $\begin{array}{l}\text { прочие социально-культурные } \\
\text { мероприятия }\end{array}$ & 24 & 12 & - & - & - \\
\hline на оборону & 19 & 9 & - & - & - \\
\hline $\begin{array}{l}\text { на содержание органов государ- } \\
\text { ственной власти и управления }\end{array}$ & 1 & 0 & 2 & 1 & 50 \\
\hline прочие расходы & 16 & 8 & 2 & 1 & 800 \\
\hline
\end{tabular}

Источник. Государственный бюджет СССР 1981-1985 (Статистический сборник). Москва. 1987 г. 214 с. 
государства между федеральным бюджетом и консолидированными бюджетами субъектов Российской Федерации. (табл. 5 и 6).

Приведенные данные свидетельствуют, что в составе доходов федерального бюджета преобладают косвенные налоги (НДС, акцизы, таможенные пошлины). Таким образом, напрашивается вывод об аналогичности структуры доходов федерального бюджета РФ и Российской империи. Данные налоги являются более надежным источником доходов по сравнению с прямыми налогами, так как практически не зависят от фазы экономического цикла.

Консолидированный бюджет субъектов РФ формируется преимущественно за счет налогов на прибыль и доход и налогов на имущество (выплачиваются за счет дохода). Остальные источники представлены долями менее $7 \%$.

Следовательно, поступление доходов в бюджеты регионов напрямую зависит от экономической динамики, а бюджетная обеспеченность в большей степени по сравнению с федеральным уровнем подвержена финансовым рискам. Сбалансированность консолидированного бюджета субъектов РФ обеспечивается безвозмездными поступлениями из федерального бюджета [9].

Таким образом, виды доходов бюджетной системы распределены между уровнями государственной власти непропорционально: объем налогов на прибыль и доход и безвозмездных поступлений на региональном уровне в 10 раз больше, чем на федеральном, а объем косвенных налогов - 20\% от поступивших в федеральный бюджет. В целом, доходы федерального бюджета на 26\% больше доходов консолидированного бюджета субъектов РФ.

Расходы федерального бюджета превышают расходы консолидированного бюджета субъектов РФ на 40\%. Анализ структуры расходов и их соотношения между уровнями государственной власти позволяет сделать вывод об относительно паритетном финансировании общегосударственных вопросов, национальной экономики, охраны окружающей среды, СМИ. Финансиро-

Таблица 5. Структура и соотношение доходов федерального бюджета (ФБ) и консолидированного бюджета субъектов Российской Федерации (КБСРФ) в 2016 году.

\begin{tabular}{|c|c|c|c|c|c|}
\hline Доходы & $\begin{array}{c}\text { ФБ } \\
\text { (млрд. руб.) }\end{array}$ & \% к итогу & $\begin{array}{c}\text { КБСРФ } \\
\text { (млрд. руб.) }\end{array}$ & \% к итогу & $\begin{array}{c}\text { Отношение } \\
\text { доходов } \\
\text { КБСРФ к } \\
\text { доходам } \\
\text { ФБ (\%) }\end{array}$ \\
\hline Всего поступлений & 13460 & 100 & 9924 & 100 & 73,7 \\
\hline Налоговые и неналоговые доходы & 13308 & 98,9 & 8289 & 83,5 & 62,3 \\
\hline налоги на прибыль и доход & 491 & 3,6 & 5299 & 53,4 & 1079,2 \\
\hline НДС, акцииз & 3289 & 24,4 & 662 & 6,7 & 20,1 \\
\hline таможенные пошлины & 1976 & 14,7 & 0 & 0,0 & 0,0 \\
\hline налоги на совокупный доход & - & - & 388 & 3,9 & - \\
\hline налоги на имущество & - & - & 1117 & 11,3 & - \\
\hline $\begin{array}{l}\text { налоги за пользование природных } \\
\text { ресурсов }\end{array}$ & 2883 & 21,4 & 69 & 0,7 & 2,4 \\
\hline государственные пошлины & 94 & 0,7 & 39 & 0,4 & 41,5 \\
\hline задолженность по налогам & 1 & 0,0 & - & - & - \\
\hline от внешнеэконом. Деятельности & 2606 & 20,0 & - & - & - \\
\hline от использования имущества & 1283 & 9,5 & 380 & 4,0 & 29,6 \\
\hline $\begin{array}{l}\text { платежи за пользование природными } \\
\text { ресурсами }\end{array}$ & 237 & 1,8 & 36 & 0,4 & 15,2 \\
\hline доходы от оказания платных услуг & 142 & 1,1 & 50 & 0,5 & 35,2 \\
\hline $\begin{array}{l}\text { доходы от продажи материальных и } \\
\text { нематериальных активов }\end{array}$ & 89 & 0,7 & 123 & 1,2 & 138,2 \\
\hline административные платежи и сборы & 26 & 0,0 & 1 & 0,0 & 3,8 \\
\hline штрафы, санкции, возмещение ущерба & 57 & 0,0 & 104 & 1,0 & 182,5 \\
\hline прочие неналоговые доходы & 134 & 1,0 & 21 & 0,0 & 15,7 \\
\hline Безвозмездные поступления & 152 & 1,1 & 1635 & 16,5 & 1075,7 \\
\hline
\end{tabular}

Источник. Рассчитано по данным: http://datamarts.roskazna.ru/ 
Таблица 6. Структура и соотношение расходов федерального бюджета (ФБ) и консолидированного бюджета субъектов Российской Федерации (КБСРФ) в 2016 г.

\begin{tabular}{|c|c|c|c|c|c|}
\hline Расходы & $\begin{array}{c}\text { ФБ } \\
\text { (млрд. } \\
\text { руб.) }\end{array}$ & \% к итогу & $\begin{array}{c}\text { КБСРФ } \\
\text { (млрд. } \\
\text { руб.) }\end{array}$ & \% к итогу & $\begin{array}{c}\text { Отношение } \\
\text { расходов } \\
\text { КБСРФ к } \\
\text { расходам } \\
\text { ФБ (\%) } \\
\end{array}$ \\
\hline Всего расходов, в том числе & 16416 & 100 & 9936 & 100 & 60,5 \\
\hline общегосударственные вопросы & 1095 & 6,7 & 625 & 6,3 & 57,1 \\
\hline национальная оборона & 3775 & 23,0 & 5 & 0,1 & 0,0 \\
\hline $\begin{array}{l}\text { национальная безопасность } \\
\text { и правоохранительная деятельность }\end{array}$ & 1900 & 11,6 & 114 & 1,1 & 6,0 \\
\hline национальная экономика & 2302 & 14,0 & 2002 & 20,4 & 87,0 \\
\hline ЖКХ & 72 & 0,4 & 936 & 9,4 & 1300,0 \\
\hline охрана окружающей среды & 63 & 0,4 & 22 & 0,2 & 34,9 \\
\hline Образование & 599 & 3,6 & 2547 & 25,6 & 425,2 \\
\hline культура и кинематография & 87 & 0,5 & 340 & 3,4 & 390,8 \\
\hline Здравоохранение & 506 & 3,1 & 1281 & 12,9 & 253,2 \\
\hline социальная политика & 4588 & 27,9 & 1654 & 16,6 & 36,1 \\
\hline физкультура и спорт & 59 & 0,4 & 212 & 2,1 & 359,3 \\
\hline СМИ & 77 & 0,5 & 43 & 0,4 & 55,8 \\
\hline обслуживание государственного долга & 621 & 3,8 & 154 & 1,5 & 24,8 \\
\hline $\begin{array}{l}\text { межбюджетные трансферты бюджетам } \\
\text { бюджетной системы }\end{array}$ & 672 & 4,1 & 1 & 0,0 & 0,0 \\
\hline
\end{tabular}

Источник. Рассчитано по данным: http://datamarts.roskazna.ru/

вание образования, здравоохранения, ЖКХ возложено преимущественно на органы власти территорий. Оборона, национальная безопасность, социальная политика, обеспечение финансовой устойчивости бюджетной системы, обслуживание государственного долга находятся в сфере финансовой ответственности федеральных органов власти. Следовательно, можно утверждать, что общество в лице депутатов возложило на федеральную власть ответственность за поддержание внутренней и внешней социально-политической стабильности, а на субфедеральную - за оказание основных социальных услуг населению.

Данная структура расходов, на наш взгляд, в большей степени напоминает распределение полномочий в Российской Империи (не считая контрольных функций, которые в настоящее время преимущественно реализуются центральным правительством, а в 2013 году возлагались на губернские органы власти). Однако, необходимо подчеркнуть, что современная Россия в отличии от империалистической де-юре является федеративным государством, делегирующим в соответствии с мировой практикой значительные полномочия на субфедеральный уровень управления [8]. В этой связи представля- ется, что в рамках совершенствования бюджетного устройства и бюджетного процесса можно, основываясь на опыте СССР, перераспределить доходные источники и расходные полномочия между ветвями государственной власти в РФ. Например, представляется целесообразным закрепить за регионами платежи за пользование природными ресурсами, паритетно распределить между центром и территориями НДС и акцизы. В этом случае можно было бы не только сократить объемы межбюджетных трансфертов, но и передать значительную долю социальных расходов на региональный уровень.

Обращает на себя внимание тот факт, что в современной бюджетной классификации расходов отсутствует раздел, связанный с финансированием науки. С учетом важности данной сферы в обеспечении конкурентоспособности отечественной экономики, здравоохранения, обороны и др. следовало бы в составе бюджетной классификации расходов выделить раздел «Фундаментальные и прикладные научные исследования» и передать полномочия по его финансированию преимущественно федеральным органам власти. 


\section{Библиографический список}

1. Горлов И. Теория финансов: сочинение Ивана Горлова: репр. изд. типографии Казанского университета типографии в 1841. Казань. 2014. 337 с.

2. Давыдов М.Д. Развитие финансового механизма администрирования доходов бюджетов бюджетной системы Российской Федерации / М.Д. Давыдов, Е.Н. Валиева, А.Г. Лукин. Москва. 2014. 146 с.

3. Евзлин 3. Бюджетный контроль и система государственной отчетности при конституционном образе правления: репр. изд. СПб.: тип. В.Я. Мильштейна, 1913. Казань. 2014. 164 с.

4. Меерович М.Г. Промышленное районирование в СССР в начальный период индустриализации // Вестник ТГАСУ. 2013. № 3. С. 132-139.

5. Налоговая система СССР. Структура налогообложения в годы СССР. 2013-2015, Приватный банковский портал - Электрон. текстовые данн.- Режим доступа: http://privathb.ru/ekonomika/ nalogovaya-sistema-sssrstruktura-nalogooblozheniya-v-gody-sssr-2.html (дата обращения: 18.04.2018). - Загл. с экрана.

6. Строков А.И. Актуальные теоретико-экономические аспекты развития бюджетного федерализма в сфере распределения властных полномочий // Экономика и предпринимательство. 2016. № 12-1 (77-1). С. 68-71.

7. Тархов С.А. Изменение административно-территориального деления России за последние 300 лет // 2001. № 15. Электрон. текстов. данные. Режим доступа: http://geo.1september.ru/articles/ (дата обращения: 18.04.2018) - Загл. с экрана.

8. Татаркин А.И. Российский налогово-бюджетный федерализм в условиях экономической нестабильности / А.И. Татаркин, Д.А. Татаркин // Федерализм. 2016. № 3 (83). С. 9-26.

9. Швецов Ю.Г. Тупик российского бюджетного федерализма // Финансы и кредит. 2017. Т. 23. № 19 (739). С. 1094-1107. 